\title{
ЦИФРОВЫЕ ТЕХНОЛОГИИ: ПРОБЛЕМЫ И ТЕНДЕНЦИИ
}

\section{Турлуев Ризван Рамзанович}

старший преподаватель

Чеченский Государственный университет

\begin{abstract}
Аннотация: Если "необходимость - мать изобретений", то Пандемия 2020 (COVID-19) заставила многих людей во всем мире переосмыслить нашу повседневную жизнь от работы до школы и развлечений. В ответ на запреты на поездки, закрытие школ и рекомендации не собираться большими группами и держаться подальше от других людей, чтобы ограничить распространение вируса, многие люди обратились к цифровым инструментам, чтобы сохранить некоторое подобие нормальности. Для того чтобы мы могли эффективно работать, крайне важно преобразовать наши места работы и образования в цифровую форму. Те компании, которые смогут хорошо использовать технологии, чтобы продолжать развиваться и переосмыслить свою бизнес-модель на будущее путем быстрой цифровой трансформации, будут опережать своих конкурентов.
\end{abstract}

Итак, цель данной статьи рассмотреть, как трансформировались цифровые технологии с 2020 года.

Ключевые слова: Цифровые технологии, ковид, пандемия, новые возможности.

Основная часть

COVID-19 ускорил цифровую трансформацию бизнеса во всех отраслях. Вот изменяющиеся аспекты бизнеса, к которым вам нужно адаптироваться в вашем цифровом переходе.

Пандемия ускорила цифровую трансформацию бизнеса во всем мире. Удаленная работа и усилия по социальному дистанцированию заставили компании принять новые способы ведения дел, меры, которые в основном включали цифровые инструменты для общения, сотрудничества и отслеживания общего прогресса. Поэтому говорить о том, что цифровая трансформация была в центре внимания с тех пор, как ударил коронавирус, кажется излишним. 


\section{ЦИФРОВИЗАЦИЯ: РОССИЯ И СНГ В КОНТЕКСТЕ ГЛОБАЛЬНОЙ ТРАНСФОРМАЦИИ}

Предпандемические преобразования в основном были обусловлены потребностями клиентов и стремлением к более эффективным и гибким процессам, но постпандемические цифровые преобразования отличаются. Здоровье и безопасность людей, расширение коммуникации и сотрудничества, социальное дистанцирование и более высокая степень адаптивности-все это теперь решающие факторы для цифровых преобразований.

Таким образом, цифровая трансформация уже является более сложным процессом, поскольку она требует от нас адаптации к новым вызовам в режиме реального времени, а также более быстрых темпов внедрения для обеспечения непрерывности бизнеса. Тем не менее, как бы ни была сложна цифровая трансформация сегодня, стало совершенно ясно, что без нее у большинства компаний нет будущего.

Пандемия COVID-19 не только поставила общество перед лицом новых глобальных проблем, но и стала причиной развития некоторых технологических трендов - к примеру, таких как онлайн-платежи, телемедицина, роботизация. [4]

Эти технологии помогают сократить распространение коронавируса, одновременно позволяя бизнесам поддерживать свою деятельность. Кроме того, подобные технологии могут помочь обществу стать более гибким и устойчивым к пандемии и другим угрозам.

Технологии не только играют решающую роль в поддержании устойчивого функционирования общества в условиях карантина и вынужденной изоляции в период пандемии, но и могут оказывать более долгосрочное влияние после окончания COVID-19.

\section{1. Онлайн-торговля и роботизированная доставка}

В конце 2002 года вспышка атипичной пневмонии (SARS) привела к значительному росту площадок онлайн-торговли в Китае - как в b2b секторе, так и в b2c. 


\section{ЦИФРОВИЗАЦИЯ: РОССИЯ И СНГ В КОНТЕКСТЕ ГЛОБАЛЬНОЙ ТРАНСФОРМАЦИИ}

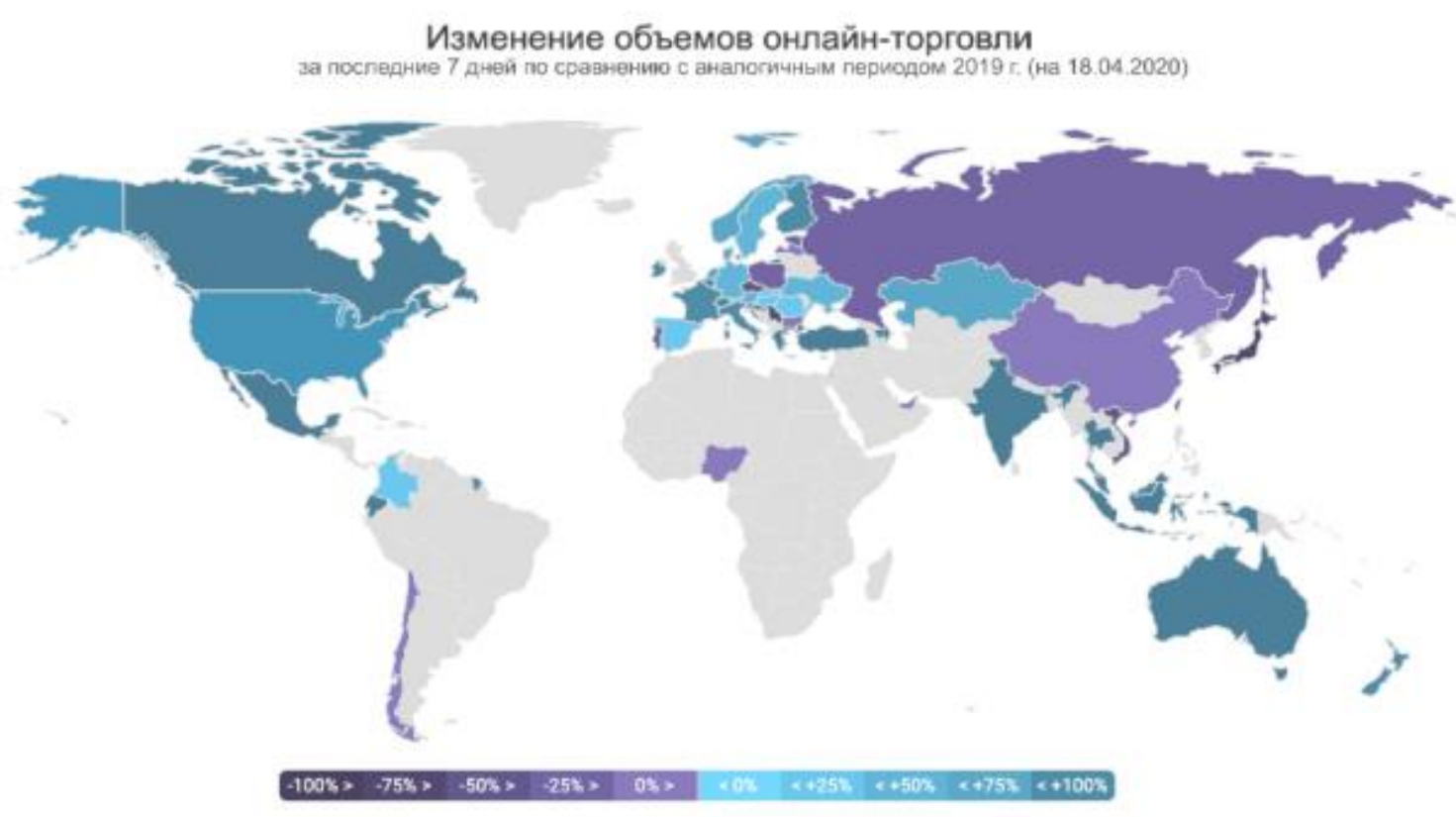

Похожим образом COVID-19 трансформировал онлайн-продажи из категории дополнительных преимуществ в разряд абсолютной необходимости для бизнесов по всему миру. Например, некоторые бары и рестораны продолжили действие акций happy hours для онлайн-заказов и доставки в период карантина. [2]

Онлайн-продажи всегда должны поддерживаться надежной системой логистики. При этом курьерская доставка не является безопасной с точки зрения угрозы передачи вируса. Поэтому многие компании, осуществляющие доставку, а также рестораны в США, Китае, России и других странах запустили сервисы бесконтактной доставки, в рамках которых передача заказа осуществляется не из рук в руки, а в конкретной локации, без непосредственного контакта между людьми.

\section{2. Электронные и бесконтактные платежи}

Наличные купюры могут способствовать распространению вируса. В связи с этим крупнейшие банки США, Китая и Южной Кореи ввели различные меры, гарантирующие безопасность банкнот до их поступления в обращение. В данный момент электронные платежи, как при помощи банковских карт, так и при помощи электронных кошельков, являются рекомендуемым методом оплаты для предотвращения распространения COVID-19. [4] 
Тем не менее, по данным Всемирного Банка, более 1,7 миллиарда человек по всему миру не имеет непосредственного доступа к электронным платежам. Их доступность, в частности, зависит от зоны покрытия интернета и обеспеченности необходимыми устройствами для обезналичивания денег.

\section{3. Удаленная работа}

Многие компании порекомендовали своим сотрудникам работать из дома. Для обеспечения удаленной работы необходимы такие технологии, как VPN (виртуальные частные сети), VoIP (передача голоса по протоколу IP), виртуальные конференции, облачные технологии, инструменты коллективной работы и даже технологии распознавания лиц, позволяющие использовать виртуальные фоны для защиты конфиденциальности жилища. При этом, помимо предотвращения распространения коронавируса, удаленная работа позволяет сэкономить время, проведенное в дороге, и обеспечивает большую гибкость графика работы для сотрудника.

\section{Скачивание приложений для удаленной работы в Китае}

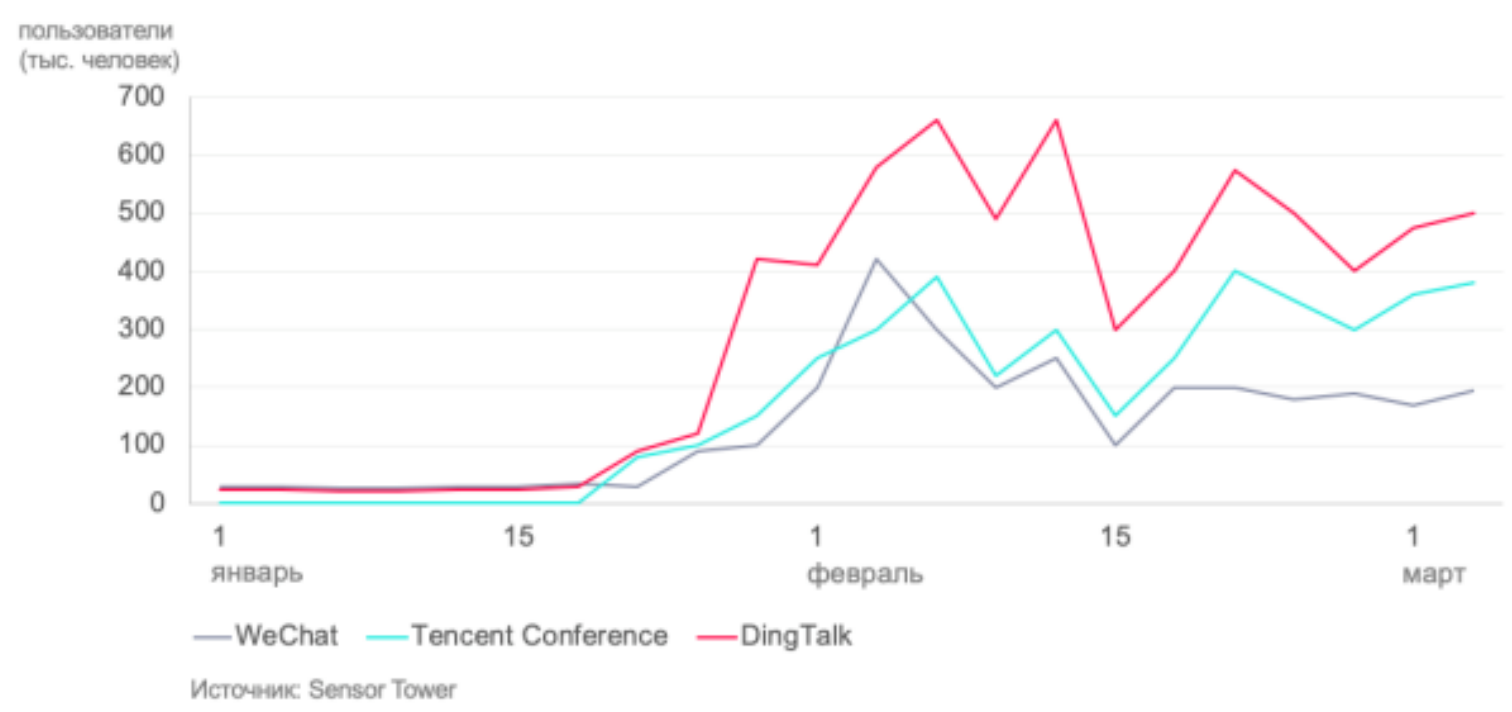

Тем не менее, удаленная работа также может создавать дополнительные сложности как для работодателей, так и для работников. Обеспечение информационной безопасности, защита конфиденциальности, своевременная техническая поддержка могут представлять проблему, как показали недавние групповые иски против Zoom. [3] 


\section{ЦИФРОВИЗАЦИЯ: РОССИЯ И СНГ В КОНТЕКСТЕ ГЛОБАЛЬНОЙ ТРАНСФОРМАЦИИ}

Кроме того, удаленная работа может усугублять конфликты, связанные с трудовым законодательством, - например, обеспечением безопасности рабочего места или вопросами налогообложения работников. Работники также могут испытывать проблемы, связанные с одиночеством и недостатком баланса между работой и частной жизнью. Если удаленная работа станет более распространенной после окончания пандемии COVID-19, вероятно, у работодателей будет больше возможностей для найма более дешевой рабочей силы из регионов, а также экономии на издержках, связанных с арендой.

Понадобится обновление законодательной базы, а также дополнительные психологические исследования для выяснения воздействия удаленной работы на людей.

Вместе с тем не любая работа может быть выполнена из дома, что приводит к неравенству. По данным Бюро статистики труда США, около 25\% работников хотя бы иногда работали удаленно в 2017-2018 году. В то же время работники с высшим образованием имеют в 5 раз больше шансов на получение должностей, позволяющих работать удаленно, чем работники со средним образованием.

Некоторые сферы, такие как медицина или производство, вовсе не предполагают возможности удаленной работы. Нормы, регулирующие передачу данных, а также налогообложение, могут потребовать пересмотра, в случае если количество трансграничных цифровых сервисов значительно вырастет.

\section{4. Дистанционное обучение}

К середине апреля 2020 года 191 страна объявила о приостановлении обучения в школах и университетах, что затронуло в общей сложности не менее 1,57 миллиарда студентов. Многие образовательные учреждения начали проводить обучение онлайн во избежание нарушения образовательных процессов карантинными мерами. Технологии, задействованные в онлайнобучении, схожи с теми, что используются при удаленной работе, а также включают технологии виртуальной реальности, дополненной реальности, 3Dпечать и использование роботов с искусственным интеллектом в качестве учителей.

Одной из проблем, связанных с дистанционным образованием, является то, что технологии могут увеличивать неравенство между людьми - как в плане готовности к цифровизации, так и в имущественном смысле. В 


\section{ЦИФРОВИЗАЦИЯ: РОССИЯ И СНГ В КОНТЕКСТЕ ГЛОБАЛЬНОЙ ТРАНСФОРМАЦИИ}

дополнение к этому дистанционное обучение может порождать экономическое давление на родителей, чаще всего женщин, которые вынуждены оставаться дома для присмотра за детьми, что, в свою очередь, может приводить к снижению их продуктивности на работе.

\section{5. Телемедицина}

Телемедицина может быть эффективным способом воспрепятствования распространению COVID-19, при полном сохранении процессов оказания первичной помощи. Носимые персональные ІоТ-устройства могут отслеживать жизненно важные показатели. Чат-боты могут ставить первоначальные диагнозы, основываясь на симптомах, предоставленных пациентом.

Однако для стран, где стоимость телемедицины высока, важно, чтобы она покрывалась медицинской страховкой. Помимо прочего, ее осуществление требует определенного уровня технической грамотности, а также стабильного интернет-соединения.

\section{6. Онлайн-развлечения}

Хотя карантинные меры значительно сократили межличностные взаимодействия, творческие усилия людей перенесли развлечения в онлайнсферу. «Облачные рейвы» и онлайн-трансляции концертов набирают обороты по всему миру; китайские кинопроизводители выпускают фильмы онлайн, музеи и объекты культурного наследия предлагают виртуальные туры. С начала эпидемии резко возрос трафик в сфере онлайн-видеоигр.

\section{7. Цепь поставок 4.0}

COVID-19 привел к сбоям в международной цепи поставок. C введением мер самоизолирования и карантина многие производства были полностью закрыты. В то время как спрос на продовольствие и средства индивидуальной защиты стремительно растет, некоторые страны ввели различные ограничительные меры на экспорт подобной продукции. Значительная зависимость от бумажного документооборота, недостаточная прозрачность данных, а также ограниченное разнообразие и гибкость поставили существующую цепь поставок в уязвимое положение относительно любой пандемии.

Ключевые технологии Четвертой Индустриальной Революции, такие как Big Data, облачные вычисления, интернет вещей и блокчейн создают 


\section{ЦИФРОВИЗАЦИЯ: РОССИЯ И СНГ В КОНТЕКСТЕ ГЛОБАЛЬНОЙ ТРАНСФОРМАЦИИ}

более устойчивую систему управления цепями поставок за счет повышения точности данных и стимулирования обмена данными. [1]

\section{3D-печать}

Для смягчения кризиса цепи поставок и последствий запретов на экспорт была развернута технология 3D-печати. 3D-печать обеспечивает гибкость процесса производства: один принтер может производить различные продукты, в зависимости от дизайна и материалов, используемых при печати, a детали могут производиться быстро, без задействования длительных процессов закупки и доставки.

Однако массовое производство с использованием 3D-печати сталкивается с некоторыми препятствиями. Во-первых, оно может встретиться с проблемами в сфере интеллектуальной собственности, если производимые детали защищены патентом. Во-вторых, производство некоторых продуктов, таких как хирургические маски, подпадает под действие нормативного регулирования, которое может требовать длительных согласований.

Другие нерешенные пока проблемы включают вопросы защиты прав на дизайн, место его происхождения и влияние на торговый оборот, а также ответственность за качество выпускаемой продукции, связанной с 3Dпечатью.

\section{9. Роботизация и дроны}

COVID-19 заставил мир осознать, насколько сильно мы зависим от человеческих взаимодействий во всех процессах. Наиболее пострадали бизнесы, связанные с трудоемкими процессами, такими как ритейл, производство пищевых продуктов, промышленность, логистика.

COVID-19 придал значительный импульс использованию роботов и исследованиям в области робототехники. За последние недели роботы использовались во всевозможных процессах — от дезинфекции поверхностей до доставки продуктов людям, находящимся на карантине. Дроны также задействовались в выгуле собак и при доставке товаров.

Несмотря на то, что некоторые доклады прогнозируют замещение многих производственных профессий роботами, в то же время в процессе будут создаваться новые рабочие места. При этом власти должны своевременно обеспечить надлежащую подготовку и социальную защиту в отношении рабочей силы для адаптации к происходящим переменам. 


\section{ЦИФРОВИЗАЦИЯ: РОССИЯ И СНГ В КОНТЕКСТЕ ГЛОБАЛЬНОЙ ТРАНСФОРМАЦИИ}

\subsection{G и информационно-коммуникационные технологии (ICT)}

Все вышеуказанные технологические тренды опираются на стабильный, высокоскоростной и доступный интернет. На фоне того, как 5G демонстрирует свою важность в процессах дистанционного наблюдения и медицинских консультаций, развертывание 5G-соединения в Европе откладывается на тот момент, когда оно будет особенно востребовано.

Переход на $5 \mathrm{G}$ приведет к росту стоимости соответствующих устройств и тарифов связи. Решение этих вопросов в обеспечении всеобщего доступа к Интернету продолжит оставаться проблемой на фоне всемирного распространения 5G-соединения.

COVID-19 продемонстрировал важность цифровизации, которая позволяет бизнесам работать, а обычной жизни - протекать в привычном ключе, насколько это возможно в условиях пандемии. Важнейшее значение как для бизнесов, так и для государств в сохранении конкурентоспособности в пост-пандемическом мире будет иметь разработка необходимой инфраструктуры для поддержки цифровизирующегося мира, сохранение актуальности на фоне стремительно развивающихся технологий, а также человекоориентированный и инклюзивный подход к управлению развитием технологий.

Примерно 200 миллионов человек потеряет работу в результате COVID19. Вместе с тем финансовое бремя чаще всего падает на самых уязвимых членов общества. Цифровизация и пандемия ускорили появление новых рабочих мест. Смягчение воздействия на рабочую силу, а также уязвимые категории населения являются задачей, стоящей перед всеми бизнесами и государствами.

Решение этой задачи требует не только особого внимания, но и своевременного, а также ориентированного на человека подхода.

Выводы

Пандемия коронавируса принесла много изменений. Она заставила всех нас искать новые способы работы, взаимодействия и жизни. Это вызвало вопросы о том, как устроены наши общества, и о том, куда мы хотим и должны инвестировать в будущем. Она показала нам наши сильные стороны и высветила наши слабые. Это поставило перед нами новые задачи, не последняя из которых-попытаться найти лекарство. 


\section{ЦИФРОВИЗАЦИЯ: РОССИЯ И СНГ В КОНТЕКСТЕ ГЛОБАЛЬНОЙ ТРАНСФОРМАЦИИ}

Карантин нанес тяжелый удар по мировой экономике. По оценкам специалистов, в этом году глобальная экономика потеряет 8-13\%. По самым оптимистичным прогнозам, только в четвертом квартале темпы роста могут вернуться к докарантинным уровням. Авиаперевозки и другие отрасли, наиболее пострадавшие от эпидемии, восстановятся не раньше 2021 года. Очевидно, что глобальная экономика уже перешла в фазу рецессии.

Однако в разгар эпидемии мы повсеместно наблюдаем явный рост потребностей в цифровых услугах. В цифровизации особенно нуждаются здравоохранение, образование, финансы, отрасль развлечений, а также компании, продолжающие работу в удаленном режиме.

Итак, Цифровые технологии - это ключевой компонент наших коллективных усилий по борьбе с вирусом и поддержке наших новых способов жизни и работы в это исключительное время. Цифровые технологии, средства массовой информации и телекоммуникации играют жизненно важную роль.

\section{Список литературы}

1. Абрамова Е.А., Капралова М.А. Роль цифровой экономики в эффективном управлении современными экономическими отношениями // Вестник Ивановского государственного университета. Серия «Экономика». Иваново, 2019. Выпуск 1/2 (39/40).

2. Демьянова О.В. Информационные технологии // Проблемы современной экономики. - 2018. - №1 (33).

3. Интервью агентству «РИА Новости» с ведущим экономистом Всемирного экономического форума Р. Кротти. М., 2020.

4. Манфред Шпитцер. Антимозг: цифровые технологии и мозг. ACT, 2015. — ISBN 978-5-457-51598-7. 